\title{
RESGATE DE EMBRIÕES IMATUROS IN VITRO DE PORTA-ENXERTOS DE MACIEIRA (Malus spp.) ${ }^{1}$
}

\author{
ADRIANA CIBELE DE MESQUITA DANTAS², JÚLIO CÉSAR DE OLIVEIRA NUNES ${ }^{3}$, LIZIANE KADINE \\ ANTUNES DE MORAES ${ }^{4}$, ENIO LUIZ PEDROTTI ${ }^{5}$, RUBENS ONOFRE NODARI ${ }^{5}$
}

\begin{abstract}
RESUMO - A cultura in vitro de embriões permite desenvolver estudos nas áreas de fisiologia e melhoramento, possibilitando o resgate de embriões imaturos, oriundos de cruzamentos que podem ser incompatíveis. Em macieira, geralmente, os embriões imaturos apresentam dormência e baixa germinação. O objetivo deste trabalho foi testar concentrações de BAP (6-benzilaminopurina) em diferentes períodos de imersão para superação da dormência e germinação de embriões imaturos de macieira. Os embriões foram extraídos de sementes retiradas de frutos oriundos do cruzamento entre os porta-enxertos de macieira Marubakaido (Malus prunifolia) x M9 (Malus pumilla), realizado em plantas matrizes cultivadas na Epagri - São Joaquim (SC). Os 50 frutos colhidos ao acaso foram submetidos a uma esterilização com etanol $96^{\circ}$ por 10 min e após com solução de hipoclorito de sódio a $2 \%$ por 20 min. As sementes foram submetidas a uma desinfestação, utilizando-se etanol $70 \%$ por $30 \mathrm{~s}$ e solução de hipoclorito de sódio $1,25 \%$ por 15 min, seguindose três lavagens com água esterilizada e autoclavada. Os embriões foram inoculados em $10 \mathrm{ml}$ de meio MS/2, suplementado com 100 mg. $\mathrm{L}^{-1}$ de mio-inositol, 30 g.L.-1 de sacarose e com BAP $\left(0,6\right.$ e 12 mg.L $\left.\mathrm{L}^{-1}\right)$ e 6 g.L.- de agar, com pH ajustado para 5,8. Os embriões foram mantidos por 24 ou 48 horas neste meio e depois transferidos para um meio MS/2 sem regulador vegetal. Não ocorreu contaminação nem oxidação em nenhum embrião. A concentração de BAP que promoveu maior crescimento dos embriões foi de $6 \mathrm{mg}$. $\mathrm{L}^{-1}$, mas o melhor aspecto quanto à intensidade de coloração e formação de brotos foi obtido utilizando-se $12 \mathrm{mg} \cdot \mathrm{L}^{-1}$.
\end{abstract}

Termos para indexação: superação da dormência, in vitro, Malus prunifolia, Malus pumilla, BAP

\section{RESCUE OF IMMATURE EMBRYOS IN VITRO OF ROOTSTOCK OF APPLE (Malus spp.)}

\begin{abstract}
The embryos culture in vitro allows studies in the physiology breeding areas, facilitating the rescue of immature embryos, originated from incompatible crossings. In apple, the immature embryos generally present dormancy and lower germination. The objective of this work was to test concentrations of BAP in different immersion periods for break of the dormancy and germination of apple immature embryos. The embryos were extracted from fruits seeds originated from the crossing between apple rootstock Marubakaido and M.9, accomplished in adult plants in Epagri - São Joaquim (SC). The 50 collected fruits were submitted to a sterilization with alcohol $96^{\circ}$ for 10 minutes and after with $\mathrm{NaClO}$ solution (2\%) for 20 minutes. The removed seeds were submitted to a disinfestations treatment with alcohol $70 \%$ for 30 seconds and with $\mathrm{NaClO}$ solution $(1,25 \%)$ for 15 minutes, followed by three washes with sterilized water and autoclaved. The embryos were inoculated in $10 \mathrm{ml}$ of MS/2 culture medium, to which was added $100 \mathrm{mg} . \mathrm{L}^{-1} \mathrm{of}$ myo-inositol, $30 \mathrm{~g} . \mathrm{L}^{-1}$ of sucrose and with BAP $\left(0,6\right.$ and $\left.12 \mathrm{mg} . \mathrm{L}^{-1}\right)$ and $6 \mathrm{~g} . \mathrm{L}^{-1}$ of agar and with $\mathrm{pH}$ adjusted to 5.8. The embryos were maintained by 24 or 48 hours in this medium and later transferred for a medium MS/2 without growth regulators. There was no contamination or oxidation. The concentration that promoted larger growth of the embryos was of $6 \mathrm{mg} . \mathrm{L}^{-1}$. However, the best general aspect in the coloration intensity and formation of sprouts was obtained when medium containing $12 \mathrm{mg}$. $\mathrm{L}^{-1}$ was utilized.
\end{abstract}

Index terms: dormancy removal, in vitro, Malus prunifolia, Malus pumilla, BAP.

\section{INTRODUÇÃO}

A técnica de cultura de embriões permite estudos nas áreas de fisiologia e melhoramento vegetal, sendo utilizada na obtenção de plantas híbridas em cruzamentos interespecíficos, onde ocorrem barreiras sexuais na formação da semente (Andreoli, 1985) ou em cruzamentos incompatíveis intra-específicos via resgate de embriões (Pasqual e Pinto, 1988).

Embriões de macieira não germinam normalmente ou apresentam problemas de desenvolvimento normal das plântulas quando colocados sobre condições adequadas para germinar.
Este fenômeno é referido como de dormência embriônica (Thenevot e Côme, 1983). Para remover a dormência embriônica em macieira, o método tradicionalmente utilizado é a estratificação, que consiste em incubar as sementes em baixa temperatura ( 2 a $4^{\circ} \mathrm{C}$ ), durante 2-3 meses (Decourtye e Brian, 1967).

Entretanto, podem ser utilizados alguns reguladores vegetais, especialmente ácidos giberélico $\left(\mathrm{GA}_{3}\right)$, conhecido como estimulador da germinação de embriões dormentes. Outro regulador vegetal, 6-benzilaminopurina (BAP), também utilizado para superar a dormência em pêssego e macieira, permite uma germinação normal com desenvolvimento das plantas sem prévia

1 Trabalho $n^{\circ}$ 132/2000. Recebido: 12/07/2000. Aceito para publicação: 25/06/2001.

2 Doutoranda em Fruticultura de Clima Temperado, FAEM/UFPAL, Pelotas, RS

3 Mestrando em Recursos Genéticos, CCA/UFSC, Florianópolis, SC

4 Bolsista de Iniciação Científica PIBIC, CCA/UFSC, Florianópolis, SC

5 Prof. Dr. Curso Pós-graduação em Recursos Genéticos, CCA/UFSC, Florianópolis, SC 
estratificação (Rouskas et al., 1980; Zhang e Lespinasse, 1991).

A possibilidade da superação da dormência embriônica de sementes de macieira pela aplicação de BAP tem grande utilidade no melhoramento de plantas, pois diminui o ciclo de geração. Poucos trabalhos com a utilização do BAP, para superação da dormência embriônica em macieira, têm sido encontrados. O objetivo deste trabalho foi verificar o efeito de diferentes concentrações de BAP, em diferentes períodos de imersão, na superação da dormência e germinação de embriões imaturos de porta-enxertos de macieira.

\section{MATERIAIS E MÉTODOS}

Foram utilizados frutos com 80 dias de idade, colhidos ao acaso em plantas M.9 (Malus pumilla Mill), após a polinização com Marubakaido (Malus prunifolia), na Estação Experimental da Epagri - São Joaquim (SC). Foram colhidos cinco frutos em cada planta do pomar, os quais foram transportados para o laboratório e submetidos à esterilização em álcool $96^{\circ}(10 \mathrm{~min}) \mathrm{e}$ solução de hipoclorito de sódio $(2 \%$; 20 min) em câmara de fluxo laminar. As sementes foram removidas, mediante corte transversal do fruto, e submetidas a uma desinfestação com etanol $70 \%$ (30s) e hipoclorito de sódio (1,25\%; 15 min), seguindo-se três lavagens com água destilada e autoclavada.

Embriões com 8mm de comprimento foram inoculados em tubos de ensaio $(25 \times 150 \mathrm{~mm})$, contendo $10 \mathrm{ml}$ de meio MS/2 (Murashige e Skoog, 1962), suplementado com 100 mg.L $\mathrm{L}^{-1}$ de mio-inositol, 30 g.L L $^{-1}$ de sacarose, BAP $(0,6$ ou 12 mg.L.- $)$ e 6 g.L. ${ }^{1}$ de ágar. $\mathrm{O} \mathrm{pH}$ foi ajustado para 5,8 antes da autoclavagem. Os embriões foram mantidos por 24 ou 48 horas neste meio de cultura, sendo então transferidos para um meio $\mathrm{MS} / 2$ sem regulador vegetal. O material foi incubado no escuro por 10 dias, sendo depois de transferido para sala de crescimento, sob fotoperíodo de 16 horas de luz $\left(40 \mu \mathrm{mol} \cdot \mathrm{m}^{-2} \cdot \mathrm{s}^{-1}\right)$, fornecidas por lâmpadas fluorescentes, brancas frias, e temperatura de $25 \pm 2^{\circ} \mathrm{C}$.

Após 30 dias, os embriões foram avaliados quanto à percentagem de contaminação, oxidação e germinação, assim como o comprimento dos embriões e seu aspecto geral. $\mathrm{O}$ aspecto geral consistiu de uma avaliação visual com atribuição de notas de 1 a 5 .

O delineamento experimental utilizado foi o inteiramente ao acaso, com quatro embriões por repetição e quatro repetições por tratamento. Os dados de comprimento foram submetidos à Análise da Regressão e os dados de aspecto geral à Análise da Variância e ao teste de separação de médias SNK (Steel e Torrie, 1980).

\section{RESULTADOS E DISCUSSÃO}

Neste trabalho, não houve contaminação nem oxidação nos embriões para todos os tratamentos testados.

Os resultados demonstraram um efeito positivo do BAP no aumento do comprimento dos embriões, quando comparados com os embriões não tratados (Figura 1). Na Figura 1, estão representadas as respostas no comprimento dos embriões às diferentes concentrações de BAP, que são crescentes até o ponto de máxima, que foi de $8,6 \mathrm{mg} . \mathrm{L}^{-1}$ de BAP, estimado pela análise de regressão.

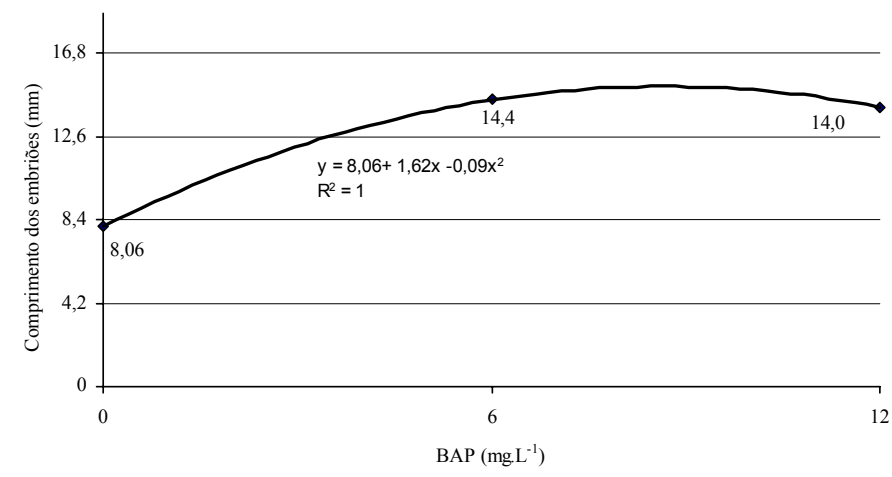

FIGURA 1 - Comprimento dos embriões imaturos do cruzamento entre os porta-enxertos de macieira Malus pumilla $x$ M. prunifolia após 30 dias de inoculação em meio de cultura suplementado com BAP. PM-ponto de máxima.UFSC, Florianópolis-SC, 1999.

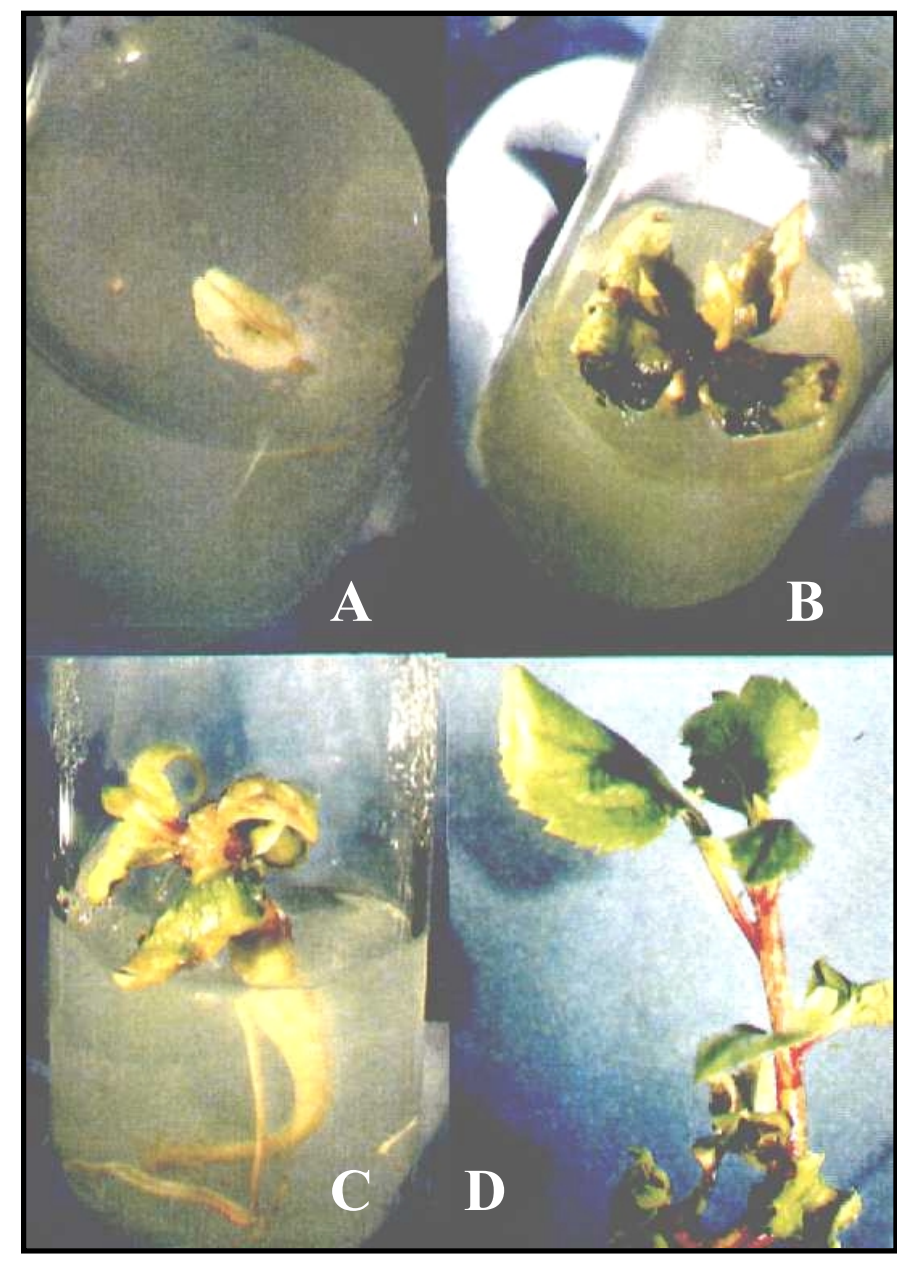

FIGURA 2 - Aspectos morfológicos do desenvolvimento de embriões imaturos do cruzamento entre os portaenxertos de macieira Malus pumilla x Malus prunifolia após 30 dias de cultivo in vitro em meio de cultura contendo diferentes concentrações de BAP. A) embrião dormente com 0 mg.. $\mathrm{L}^{-1}$ de BAP. B) 24 horas de imersão em 6,0 $\mathrm{mg} . \mathrm{L}^{-1}$ de BAP; C) 24 horas de imersão em $12 \mathrm{mg} . \mathrm{L}$ ${ }^{1}$ de BAP; D) 48 horas de imersão em 12 mg.L-1 ${ }^{-1}$ de BAP. UFSC, Florianópolis-SC, 1999. 


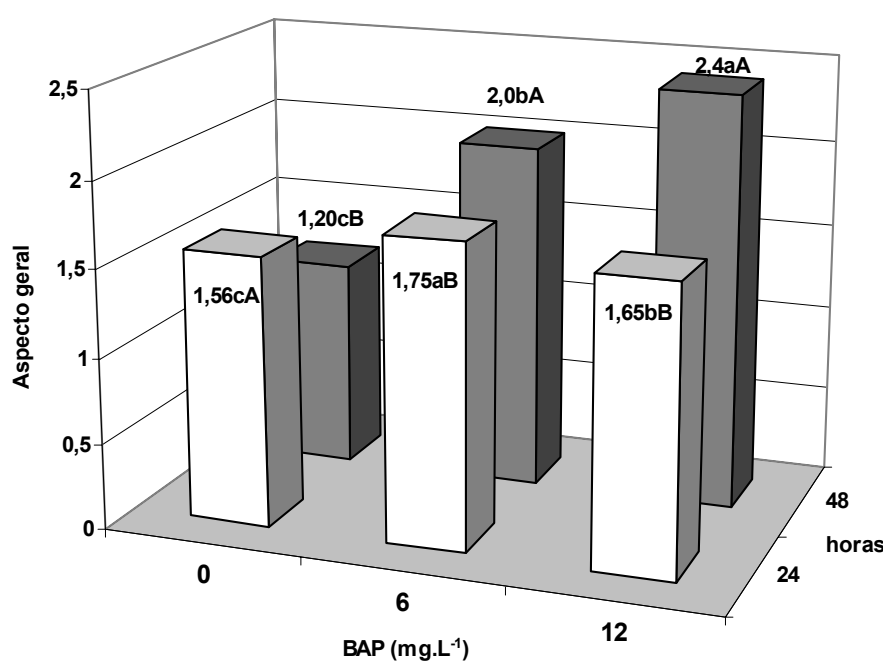

FIGURA 3 - Aspecto geral de embriões imaturos do cruzamento entre os porta-enxertos de macieira Malus pumilla $x$ Malus prunifolia após 30 dias de cultivo in vitro em meio de cultura contendo diferentes concentrações de BAP, combinadas com diferentes períodos de imersão. UFSC, Florianópolis-SC, 1999. Letras iguais não diferem pelo Teste SNK (as comparações entre as letras minúsculas são feitas para as diferentes concentrações de BAP, e as letras maiúsculas são feitas para comparações entre períodos de imersão).

A premissa de que embriões de macieira são dormentes após a colheita (Krugman et al., 1974), foi confirmada neste trabalho, onde em meio de cultura livre de BAP não foi observado o desenvolvimento do embrião. Já com 24 horas de imersão em meio de cultura suplementada com $6,0 \mathrm{mg} . \mathrm{L}^{-1}$ de BAP, os embriões apresentaram um entumescimento e alargamento do eixo embrionário e brotações aclorofiladas sem desenvolvimento da radícula, que, de acordo com a literatura, confirma como um desenvolvimento anormal dos seedlings (Figura 2). O mesmo fora observado anteriormente por Bulard (1985) e Roen (1994), onde a aplicação de citocinina incrementou a germinação de embriões e inibiu o seu crescimento, e que altas concentrações favoreceram o alargamento do hipocótilo e epicótilo.

Na concentração de $12 \mathrm{mg} . \mathrm{L}^{-1}$ de BAP, com 24 horas de imersão, observaram-se melhor desenvolvimento foliar e produção de raízes com maior diâmetro. Contudo, com 48 horas de imersão, as plantas mostraram-se vitrificadas (Figura 2). Quanto ao aspecto geral (Figuras 2 e 3), a melhor resposta foi obtida com 48 horas de imersão em meio de cultura contendo 12 mg.L ${ }^{-1}$ de BAP.

Algumas anormalidades de cotilédones e radícula podem ser responsáveis pela baixa germinação e pelo crescimento anormal de seedlings. Possivelmente em estágio mais desenvolvido dos embriões, possa ocorrer uma melhor absorção nutricional do endosperma, resultando em desenvolvimento normal dos seedlings (Ivanicka e Mokrá, 1982).

O estádio de desenvolvimento dos embriões pode ter restringido o efeito do BAP sob sua germinação, pois Durand (1974) conseguiu remover a dormência embriônica em macieira com o uso de BAP, mas obteve uma baixa germinação. Já Rouskas et al. (1980) obtiveram germinação normal com a imersão de embriões de porta-enxerto de pessegueiro em $200 \mathrm{mg} . \mathrm{L}^{-1}$ de BAP por 24 horas. Entretanto, em altas concentrações de citocininas (50-200 mg.L $\mathrm{L}^{-1}$ ), Zhang e Lespinasse (1991) observaram em embriões imaturos da cv. Golden Delicious a indução de uma maior quantidade de plantas anormais do que em baixas concentrações $\left(12,5-25,0 \mathrm{mg} \cdot \mathrm{L}^{-1}\right)$.

Vários trabalhos realizados com embriões dormentes em diferentes espécies têm estabelecido que a dormência é controlada pelo balanço de inibidores e promotores de crescimento, onde auxinas, giberilinas e citocininas podem servir como promotores e, que o ácido abscísico (ABA) é provavelmente um hormônio importante que faz parte de um complexo inibitório (Côme, 1981; Perino e Côme, 1991).

Na complementação deste trabalho, outras estratégias poderiam ser utilizadas no cultivo de embriões imaturos de portaenxertos de macieira, como testes de meio de cultura contendo caseína hidrolisada, ácido giberélico e diferentes fontes e concentrações de citocininas, a fim de eliminar ou diminuir alguns dos distúrbios morfológicos encontrados no desenvolvimento das plantas.

\section{CONCLUSÕES}

1 - As concentrações e o tempo de imersão com BAP mostraram eficiência na superação de dormência, porém não foram eficientes na formação de plantas normais.

2 - Em termos práticos, o resgate de embriões pode assegurar a superação da dormência e a obtenção e clonagem de plantas através da micropropagação, possibilitando a diminuição do período para testes nas plantas em programas de melhoramento genético.

\section{AGRADECIMENTOS}

Agradecemos à Estação Experimental de São Joaquim, da EPAGRI, pelo fornecimento de frutos para a realização deste trabalho. Também agradecemos aos assessores pelas valiosas contribuições à melhoria do manuscrito.

\section{REFERÊNCIAS BIBLIOGRÁFICAS}

ANDREOLI, C. Cultura de embriões. In: SIMPÓSIO DE CULTURA DE TECIDOS VEGETAIS, 1., Brasília. Anais... p.2528.

BULARD, C. Intervention by gibberellin and citokinin in the release of apple embryos from dormancy: A reappraisal. New Phytologyst, Cambridge, v. 101, p.241-249, 1985.

CÔME, D. Problems of embryonal dormancy as exemplified by apple embryo. Israel Journal of Botany, Jerusalem, v.29, p.145156, 1981.

DECOURTYE,L.; BRIAN, C. Détermination des besoins en froid 
des pépins de Pomacées. Interprétation descourbes de germination. Ann. Amélior. Plantes, v.17, p.375-391, 1967.

DURAND, M. Influence de quelques régulateurs de croissance sur la germination et la dormance de lémbryon de pommier (Pyrus malus L.). 1974. , 68p. These (Doctorat) - Universidade de Paris, Paris, 1974.

IVANICKA, J.; MOKRÁ, A. Development and cultivation of early-ripening cherry embryos. Biologia-Bratislava, v.37, n.1, p.312, 1982.

KRUGMAN, S.L.; STEIN, W.I.; SCHMTT, D.M. Seed biology. In: SCHOPMEYERS, C. S. (Ed.) Seed of woody plants in the United States. Washington: Forest Service, U.S. Depart. Of Agriculture, 1974. p. 1-40.

MURASHIGE, T.; SKOOG, F. A revised medium for rapid growth and bioassays with tobacco tissue cultures. Physiologia Plantarum, Copenhagen, v.15, p.473-497,1962.

PASQUAL, M.; PINTO, J.E.B.P. Cultura de embriões. Notícias da Associação Brasileira de Cultura de Tecidos de Plantas, Brasília, v.9, p.2-12, 1988.

PERINO, C., CÔME, D. Physiological and metabolical study of the germination phases in apple embryo. Seed Science \&
Technology, Zurich, v.19, p.1-14, 1991.

ROEN, D. Prospects for shortening the breeding cycle of apple (Malus $x$ domestica Borkh.) using embryo culture. I. Reducing the period of cold treatment by hormone application. Gartenbauwissenschaft, Stuttgart, v.59, n.2, p.49-53, 1994.

ROUSKAS, D.; HUGARD, J.; JONARD, R.; VILLEMUR, P. Contribution à l'étude de la germination des graines de pêcher (Prunus persica Batsch) cultivar INRA-GF305: effects de la benzyl-amino-purine (BAP) et les gibbérellines $\mathrm{GA}_{3}$ et $\mathrm{GA}_{4+7}$ sur la levée de dormance embryonnaire et l'abscence des anormalies foliaires observées sur les plantes issues de graines non stratifées. C.R. Acad. Science Sér. , Paris, v.291, p. 861-864, 1980.

STEEL, R.G.D., TORRIE, J.H. Principles and procedures of statistics - a biometrical approach. 2.ed. New York: McGraw-Hill Book, 1980.633p.

THÉNEVOT, C.; CÔME, D. Corrélations physiologiques entre láxe et les cotylédons des embryos dormantes. Bull. Soc. Bot. Fr., v.130, p.79-88, 1983.

ZHANG, Y.X.; LESPINASSE, Y. Removal of embryonic dormancy in apple (Malusxdomestica Borkh.) by 6-benzylaminopurine. Scientia Horticulturae, Amsterdam, v.46, p.215-223, 1991. 